\title{
Concepções docentes em relação à promoção do ensino de Ciências da Natureza nos anos iniciais do Ensino Fundamental
}

\section{Teaching conception in relation to the promotion of nature sciences teaching in the first years of fundamental education}

\author{
Débora Luana Kurz (kurz.deboraluana@gmail.com) \\ Mestre em Ensino de Ciências, Universidade Luterana do Brasil \\ Rene Miguel da Silva (renets_miguael@ hotmail.com) \\ Graduando do curso de Licenciatura em Química, Universidade Federal do Paraná.
}

Everton Bedin (bedin.everton@gmail.com)

Doutor em Educação em Ciências: Química da Vida e Saúde, Universidade Federal do Paraná

\section{Claudia Lisete Oliveira Groenwald (claudiag@ulbra.br)}

Doutora em Ciências da Educação, Universidade Luterana do Brasil

Resumo: O presente estudo, recorte de uma pesquisa de mestrado, tem por objetivo analisar a concepção docente em relação ao ensino de Ciências no que se refere às implicações deste nos processos de ensino e aprendizagem dos objetos de conhecimentos da área, bem como aos indicativos que conduziram as docentes a escolha pela profissão. Neste viés, esta pesquisa adota os pressupostos de um estudo de caso de cunho etnográfico mediante uma perspectiva qualitativa, à luz da colaboração de 7 professoras de turmas de $1^{\circ}$ e $2^{\circ}$ anos do Ensino Fundamental, oriundas de escolas de Vera Cruz, Estado do Rio Grande do Sul. Neste desenho, os achados da pesquisa possibilitam entender que as professoras possuem lembranças positivas e pertinentes sobre a área, porém poucos indícios práticos destas percepções foram identificados no espaço escolar, considerando que somente em pontuais e específicos momentos se propiciou discussões a respeito da área. Do mesmo modo, identificou-se, enquanto fatores que conduziram as docentes à profissão professor, aspectos como: afinidade, influências e necessidade. Sendo assim, pontua-se a importância de fomentar ações voltadas à formação contínua de professores, visando dialogar a respeito dos quesitos que emergem ao longo deste estudo.

Palavras-chave: Ensino de Ciências da Natureza; Anos iniciais do Ensino Fundamental; Concepção docente.

Abstract:The present study is an excerpt from a master's research, which aims to analyze the teaching concept in relation to science teaching, with regard to its implications in the teaching and learning processes of knowledge objects in the area, as well as indications that led them to choose the teaching profession. In this perspective, this research adopts the assumptions of a case study of an ethnographic nature through a qualitative perspective, as well as the collaboration of 7 teachers from the 1st and 2nd 
years of elementary school, from schools in Vera Cruz, State of Rio Grande do Sul. In this bias, the research findings lead us to believe that teachers have positive memories and are very relevant to the area, but little evidence of these perceptions was identified from the school space, considering that only in specific and specific moments were discussions about the area. In the same way they were identified, as factors that led them to the teaching profession, aspects such as: affinity, influences or even need. Therefore, there is a need to promote actions aimed at continuing teacher education, aiming to dialogue about the issues that emerge throughout this study.

Keywords: Teaching of Natural Sciences; Initial years of Elementary School; Teaching conception.

\section{INTRODUÇÃO}

O ensino de Ciências da Natureza nos anos iniciais do Ensino Fundamental, em conformidade a Lorenzetti e Delizoicov (2001), tende a propiciar ao estudante a construção e a atribuição de seus primeiros sentidos e significados sobre os fenômenos que permeiam o mundo, de modo a ampliar os seus conhecimentos e a sua cultura. Isto é, além de se caracterizar como uma possibilidade de o sujeito interpretar o mundo, o ensino de Ciências da Natureza consiste em uma estratégia para fomentar a sua participação nos processos de tomada de decisões frente a questões relativas a sociedade na qual se encontra inserido. Deste modo, o ensino de Ciências tem como compromisso a "formação do cidadão cientificamente alfabetizado, capaz de não só identificar o vocabulário da ciência, mas também de compreender conceitos e utilizá-los para enfrentar desafios e refletir sobre seu cotidiano" (KRASILCHICK; MARANDINO, 2007, p. 19).

Nessa teia, parte-se da premissa que promover o acesso e o desenvolvimento do conhecimento relativo ao ensino de Ciências desde o ingresso da criança na escola tende a ser decisivo para a sua formação científica (PIZARRO; JUNIOR, 2016). Em corroboração, Fumagalli (1998) salienta que ao ensinar Ciências às crianças não se está preocupado somente com a formação de futuros cidadãos, pois estas, como sujeitos sociais, integram a sociedade, sendo também responsáveis pelas decisões conscientes, responsáveis e solidárias voltadas ao bem-comum da comunidade em que se encontram inseridas. Ainda, a autora mencionada, ressalva o compromisso da escola em mediar tal processo, de modo a socializar e difundir os conhecimentos científicos, sejam estes 
Edição Especial: I SSAPEC - Simpósio Sul-Americano de Pesquisa em Ensino de Ciências

ISSN: 2595- $4520 \quad$ Vol. 4, n. 3. 2021

conceituais, procedimentais ou atitudinais, a fim de propiciar ao sujeito a oportunidade de sistematizar, ampliar e contextualizar os seus saberes.

Todavia, a ação docente tem um papel vital em relação a este processo, visto que a mesma possui a responsabilidade de promover o acesso e a mediação do conhecimento científico, com vistas a formação de um sujeito crítico e reflexivo. Neste aporte, destaca-se que cabe ao professor orientar o estudante ao longo deste processo, bem como promover a abordagem contextualizada de tais saberes, mediante o uso de distintas estratégias de ensino, no intuito de fomentar a participação ativa do sujeito ao longo deste processo (VIECHENESKI; CARLETTO, 2013). Assim, propiciar uma educação científica para todos é imprescindível, visto que, além de se tratar de uma demanda econômica e social, se constitui como um direito de todos (MARANDINO; KRASILCHIK, 2004; CACHAPUZ et al., 2005).

No entanto, pesquisas apontam as dificuldades dos docentes em relação ao ensino de Ciências em detrimento de uma formação polivalente, aspecto que tende a implicar na abordagem de tais saberes (LORENZETTI; DELIZOICOV, 2001; VIECHENESKI; CARLETTO, 2013; KURZ; BEDIN, 2019). Esta lacuna na formação docente tende a influenciar, sobretudo, no modo em que os objetos de conhecimento são desenvolvidos no espaço escolar, comumentemente, de modo estático e descontextualizado. Este desenho representa um aspecto que tem dificultado ao estudante compreender a correlação entre o científico e o seu contexto, bem como a possibilidade de o mesmo atribuir sentido e significado aos assuntos em discussão (LORENZETTI; DELIZOICOV, 2001).

Com base nestas premissas, este artigo tem como objetivo analisar a concepção docente em relação ao ensino de Ciências da Natureza no que se refere às implicações desta no acesso e na mediação do conhecimento científico nos anos iniciais do Ensino Fundamental. Do mesmo modo, ao longo deste texto, buscou-se identificar indicativos que conduziram o grupo de professoras participantes desta pesquisa a escolha da profissão. Este artigo é importante na medida em que se compreende que a concepção do professor em relação ao ensino de Ciências reflete em sua prática docente (OVIGLI; BERTUCCI, 2009). Afinal, Goldschmidt, Júnior e Loreto (2014, p. 134) afirmam que as diferentes concepções em relação à área tendem a influenciar as práticas pedagógicas 
Edição Especial: I SSAPEC - Simpósio Sul-Americano de Pesquisa em Ensino de Ciências ISSN: 2595- $4520 \quad$ Vol. 4, n. 3. 2021

desenvolvidas pelos professores, podendo estes disseminarem "visões da Ciência que se afastam notoriamente da forma como se constrói o conhecimento científico".

Em corroboração, Bedin e Del Pino (2018, p. 224) expõem que "o professor tem percebido, de forma exacerbada, que vive sua prática oscilando entre valorização e desvalorização, muitas vezes perdendo a própria identidade que ele, durante o tempo de formação e atuação, constituiu no coletivo e no individual”. Isto é, a profissão professor, com ênfase no ensino de Ciências, apresenta "significados e experiências que se interrelacionam com o contexto em que é exercida e com a formação, considerando a identidade do próprio profissional” (BEDIN; DEL PINO, 2018, p. 224).

\section{METODOLOGIA}

Esta pesquisa adota os pressupostos de um estudo de caso de cunho etnográfico, mediante uma perspectiva qualitativa de investigação, com o intuito de analisar a partir de lembranças e de memórias de professoras as suas concepções em relação ao ensino de Ciências da Natureza, no que se refere às implicações desta no acesso e na mediação do conhecimento científico nos anos iniciais do Ensino Fundamental, assim como indicativos que os conduziram a profissão professor. Para tanto, esta pesquisa conta com a colaboração de um grupo de 7 professoras de turmas de $1^{\circ}$ e $2^{\circ}$ anos do Ensino Fundamental, oriundas de 3 escolas da rede pública de ensino do município de Vera Cruz, Estado do Rio Grande do Sul (RS).

Nessa perspectiva, em conformidade a Sarmento (2011), destaca-se que a investigação se refere a um estudo de caso porque este consiste em uma pesquisa voltada à investigação da natureza singular do objeto de incidência. Ademais, a imposição da perspectiva etnográfica em um estudo de caso propicia "uma orientação do olhar investigativo para os símbolos, as interpretações, as crenças e valores que integram a vertente cultural" (SARMENTO, 2011, p. 16). Desse modo, optou-se por uma abordagem qualitativa, visto que Minayo (2014, p. 1105) destaca que esta tem como objetivo "compreender o sentido ou a lógica interna que os sujeitos atribuem a suas ações, representações, sentimentos, opiniões e crenças".

No que tange o processo de coleta de dados, salienta-se que os mesmos derivaram de uma entrevista semiestruturada com o grupo de professoras, de um questionário 
Edição Especial: I SSAPEC - Simpósio Sul-Americano de Pesquisa em Ensino de Ciências

ISSN: 2595- $4520 \quad$ Vol. 4, n. 3. 2021

composto por questões abertas e fechadas voltadas ao objetivo desta pesquisa, sendo este disponibilizado em formato físico, e, além da observação do cotidiano escolar, donde derivou-se as descrições em um diário de bordo, dos materiais dos estudantes das respectivas turmas envolvidas. A análise, por sua vez, foi realizada mediante a triangulação dos dados obtidos, sendo estes interpretados à luz da literatura vigente.

\section{RESULTADOS E DISCUSSÃO}

Com vistas ao objetivo proposto para esta pesquisa, o qual consiste em discutir a concepção das professoras em relação ao ensino de Ciências da Natureza no início do processo de escolarização, no que tange a promoção do acesso e a mediação do conhecimento científico, a partir de suas memórias, buscou-se compreender se as professoras colaboradoras da pesquisa quando estudantes da Educação Básica gostavam das aulas de Ciências. Do mesmo modo, teve-se como pretensão, ao longo deste estudo, evidenciar indicativos de fatores que as conduziram à profissão professor.

Para tanto, buscou-se descrever, de forma breve, o perfil das colaboradoras da pesquisa no intuito de elucidar aspectos como formação, experiência docente e outras informações pertinentes à trajetória enquanto profissional da educação. Sendo assim, considerando as três escolas envolvidas, as professoras participantes da pesquisa são identificadas por meio das seguintes siglas: as professoras da escola A: professora do $1^{\circ}$ ano do EF (PA1) e professora do $2^{\circ}$ ano do EF (PA2); as professoras da escola B: professora do $1^{\circ}$ ano do $\mathrm{EF}(\mathrm{PB} 1)$ e professora do $2^{\circ}$ ano do $\mathrm{EF}(\mathrm{PB} 2)$; e as professoras da escola $\mathrm{C}$ : professora do $1^{\circ}$ ano do $\mathrm{EF}$ (PC1), professora estagiária do $1^{\circ}$ ano do EF (PEC1) e professora do $2^{\circ}$ ano do EF (PC2). As informações relativas a esta questão encontram-se dispostas no Quadro 1:

Quadro 1 - Recorte das informações relativas ao perfil das professoras envolvidas na pesquisa.

\begin{tabular}{|cc|}
\hline Prof. & \multicolumn{1}{c|}{ Colocações extraídas da entrevista } \\
\hline & A professora da turma do $1^{\circ}$ ano do Ensino Fundamental, da escola localizada \\
no interior do munícipio de Vera Cruz/RS, é formada em Pedagogia e possui \\
pÁs-graduação em alfabetização e letramento. A mesma salienta que possui \\
aproximadamente 13 anos de experiência docente, dos quais 7 anos são na \\
escola em que ocorre a pesquisa e, do respectivo espaço temporal, a maioria \\
deste com turmas de $1^{\circ}$ e $2^{\circ}$ anos. No que tange o processo formativo, a
\end{tabular}




\begin{tabular}{|c|c|}
\hline & $\begin{array}{l}\text { tadas a discussão e reflexão sobre a prática docente, visto que se } \\
\text { ontrava em licença maternidade. }\end{array}$ \\
\hline PA2 & $\begin{array}{l}\text { A professora da turma do } 2^{\circ} \text { ano do Ensino Fundamental, da escola localizada } \\
\text { no interior do munícipio de Vera Cruz/RS, além de ser formada em } \\
\text { Pedagogia, possui pós-graduação em psicopedagogia clínica e institucional. } \\
\text { Ademais, possui aproximadamente } 20 \text { anos de docência, sendo que destes } 3 \\
\text { anos são de atuação na escola A. Do mesmo modo, a PA } 2 \text { costuma participar } \\
\text { de um momento de formação continuada de professores ao ano, e salientou } \\
\text { que em } 2019 \text { participou de uma série de encontros para a discussão e a } \\
\text { implantação da BNCC. }\end{array}$ \\
\hline PB1 & $\begin{array}{l}\text { A professora do } 1^{\circ} \text { ano do Ensino Fundamental da escola situada no centro do } \\
\text { município de Vera Cruz/RS possui } 31 \text { anos de experiência docente, dos quais } \\
7 \text { anos atuando na escola B. Inicialmente possuía a formação de magistério, e } \\
\text { somente após alguns anos, em função de mudanças na legislação, ingressou e } \\
\text { se formou no curso de Pedagogia. Ao longo de sua profissão, atuou em } \\
\text { diferentes escolas, assim como já foi responsável pela direção e coordenação } \\
\text { pedagógica. Possui o hábito de participar de momentos formativos, em média } \\
\text { de } 2 \text { por ano. Todavia, ressalva que em } 2019 \text { participou de vários encontros } \\
\text { propostos pela Secretaria Municipal de Educação, para diálogos sobre a } \\
\text { BNCC. No momento, está parcialmente aposentada ( } 20 \text { horas). }\end{array}$ \\
\hline PB2 & $\begin{array}{l}\text { A professora da turma do } 2^{\circ} \text { ano do Ensino Fundamental da escola situada no } \\
\text { centro do município de Vera Cruz/RS é formada em Pedagogia, porém } \\
\text { diferentemente das demais, é um curso no formato EaD (Educação a } \\
\text { Distância). Esta possui aproximadamente } 10 \text { anos de experiência, dos quais } 1 \\
\text { ano e } 4 \text { meses atuando na escola } \mathrm{B} \text {, e, portanto, encontra-se em período de } \\
\text { estágio probatório, pelo fato de ser concursada. Em relação a formação } \\
\text { continuada de professores, a PB2 afirma que costuma participar de vários } \\
\text { encontros, e assim como as demais, ressalta que a Secretaria Municipal de } \\
\text { Educação promoveu eventos para a discussão sobre a BNCC. }\end{array}$ \\
\hline PC1 & $\begin{array}{l}\text { professora da turma do } 1^{\circ} \text { ano do Ensino Fundamental da escola que se } \\
\text { contra localizada em um dos bairros do munícipio supracitado é formada } \\
\text { n Pedagogia e possui } 7 \text { anos de experiência docente, todo este período } \\
\text { uando apenas na escola C. Ao mesmo tempo, afirma que nos últimos dois } \\
\text { os participou de mais de } 3 \text { eventos voltados a formação continuada de } \\
\text { ofessores, além dos momentos propostos pela Secretaria Municipal de } \\
\text { ducação de Vera Cruz/RS. }\end{array}$ \\
\hline PEC1 & $\begin{array}{l}\text { A professora estagiaria da turma do } 1^{\circ} \text { ano do Ensino Fundamental da escola } \\
\text { C, está cursando os últimos semestres do curso de Pedagogia em uma } \\
\text { universidade comunitária da região. Quanto a sua experiência, a mesma } \\
\text { ressalta que atua na mesma escola como monitora, sendo responsável por } \\
\text { acompanhar estudantes com deficiência, função que a mesma exerce a } \\
\text { aproximadamente } 3 \text { anos. Ademais, possui o hábito de participar, ao menos } \\
\text { uma vez ao ano, de momentos voltados a área, porém, pelo fato de ser } \\
\text { monitora, a mesma não pode participar das discussões sobre a BNCC. }\end{array}$ \\
\hline PC2 & $\begin{array}{l}\text { A professora do } 2^{\circ} \text { ano do Ensino Fundamental da escola } \mathrm{C} \text { é formada em } \\
\text { Pedagogia e possui pós-graduação em psicopedagogia institucional. Esta } \\
\text { possui em média } 10 \text { anos de experiência em sala de aula, e deste período } \\
\text { somente } 7 \text { meses atuando na escola mencionada. Ademais, a mesma ressalva }\end{array}$ \\
\hline
\end{tabular}


ter participado de 4 momentos de formação continuada nos últimos dois anos.

Fonte: Dados da pesquisa.

Dando prosseguimento a discussão, na entrevista com o grupo de professoras, se indagou-as a expressarem os motivos que as conduziram a ser professoras de turmas dos anos iniciais do Ensino Fundamental. Este processo é importante para entender, mesmo que superficialmente, a identidade docente construída, visto que há implicações de um conjunto de variáveis nesta escolha, desde oportunidades, investimentos, disposições em relação ao futuro como profissional, dentre outras (CAMPOS, 2008). Nesse sentido, no intuito de compreender a escolha pela respectiva profissão, apoia-se na entrevista realizada de forma individual com cada uma das participantes, sendo uma síntese das respostas obtidas disposta no Quadro 2:

Quadro 2 - Recorte das entrevistas realizadas com o grupo de professoras em relação as motivações que as conduziram a profissão professor.

\begin{tabular}{|c|c|}
\hline Prof. & Colocações extraídas da entrevista \\
\hline PA1 & $\begin{array}{l}\text { Uma das motivações para seguir a carreira docente, era a irmã mais jovem que } \\
\text { precisava de auxílio na realização das atividades escolares, e outro foi um } \\
\text { estágio supervisionado realizado, ainda no Ensino Médio, em uma escola de } \\
\text { Educação Infantil de Vera Cruz/RS. }\end{array}$ \\
\hline PA2 & $\begin{array}{l}\text { Embora não houvesse um interesse pontual na respectiva profissão, uma } \\
\text { amiga de PA2 havia lhe incentivado a se matricular em uma escola que } \\
\text { ofertava o curso de magistério. Ingressando no mesmo, acabou se } \\
\text { identificando, principalmente com os estágios, dando continuidade aos } \\
\text { estudos. }\end{array}$ \\
\hline PB1 & $\begin{array}{l}\text { Salienta que possuía interesse em áreas como: turismo, secretariado executivo } \\
\text { ou ainda algo relacionado a idiomas, e afirma que não queria professora, } \\
\text { apesar de mãe e irmã, terem seguido esta profissão. Mas alguns percalços da } \\
\text { vida lhe conduziram a se matricular no magistério. A partir de então, começou } \\
\text { a se identificar com a profissão, especialmente, com os estagios } \\
\text { supervisionados. }\end{array}$ \\
\hline PB2 & $\begin{array}{l}\text { A PB2 também não queria ser professora, e complementa sua fala } \\
\text { demonstrando interesse pelo curso de fisioterapia. No entanto, em função de } \\
\text { exigências de sua mãe, realizou a matrícula no magistério, segundo a mesma: } \\
\text { "fiz por causa dela" - (Recorte da entrevista com a professora PB2). Sendo } \\
\text { assim, a PB2 salienta que cursou o Magistério e na sequência o curso de } \\
\text { Pedagogia. Ela complementa, que no presente momento já não consegue se } \\
\text { imaginar em outra profissão. }\end{array}$ \\
\hline PC1 & $\begin{array}{l}\text { sde criança, sempre sonhou em ser professora. Dentre suas } \\
\text { es, ressalta as brincadeiras com a vizinhança. A PC1 complementa, } \\
\text { scrição do vestibular, na qual era possível realizar a inscrição em três } \\
\text { mesma ressalva que "não adiantava eu colocar segunda ou terceira }\end{array}$ \\
\hline
\end{tabular}




\begin{tabular}{|c|c|}
\hline & $\begin{array}{l}\text { çao - (Recorte da entrevista de PC1), porque nao possuia interesse em } \\
\text { tro curso além de Pedagogia. }\end{array}$ \\
\hline PEC1 & $\begin{array}{l}\text { Afirma nunca ter pensando em ser professora, principalmente dos anos } \\
\text { iniciais, visto que sempre trabalhou em uma área muito distinta. Porém ao ser } \\
\text { selecionada em um concurso para trabalhar em escolas, e em função de uma } \\
\text { colega de trabalho bastante proativa, passou a ter interesse pela área, o que } \\
\text { levou PEC } 1 \text { a ingressar no curso de Pedagogia. Sendo assim, no presente } \\
\text { momento a mesma está realizando o estágio supervisionado, e complementa } \\
\text { que ainda possui muitas dificuldades em relação ao exercício docente. }\end{array}$ \\
\hline PC2 & $\begin{array}{l}\text { Embora tivesse interesse em ser professora, a PC2 salienta que após concluir } \\
\text { o Ensino Médio, começou a trabalhar como cabeleireira, em um instituto de } \\
\text { beleza. No entanto, após alguns anos a respectiva profissão já não lhe trazia } \\
\text { mais satisfação, e optou por ingressar no curso de Pedagogia. Assim durante a } \\
\text { graduação, durante o dia trabalha no instituo de beleza, e a noite, realizava as } \\
\text { disciplinas. Após formada, logo conseguiu um contrato para trabalhar em uma } \\
\text { escola da região. }\end{array}$ \\
\hline
\end{tabular}

Fonte: Dados da pesquisa.

Nesse contexto, considerando o exposto no Quadro 2, apresenta-se os distintos aspectos que conduziram as docentes ao curso de Pedagogia. Para tanto, destaca-se que as professoras PA1, PC1 e PC2 sempre demostravam afinidade pela profissão mencionada, enquanto que as professoras PA2, PB1, PB2, e PEC1 não possuíam interesse em seguir a profissão professor, somente em decorrência das particularidades ao longo deste processo, bem como por influências de familiares e/ou amigos próximos. Ademais, um ponto em comum nas narrativas das colaboradoras refere-se a necessidade financeira que, articulada ao contexto, pode ter influenciado para a escolha da profissão.

Estas afirmações podem também ser observadas em função da frequência dos indícios em que emergem ao longo da entrevista, os quais foram computados e apresentados na Tabela 1:

Tabela 1 - Categorias que emergiram frente aos motivos pela escolha da profissão.

\begin{tabular}{lcc}
\hline Categorias & Frequência & Percentual \\
\hline Afinidade com a profissão & 32 & $55,17 \%$ \\
\hline Influências & 18 & $31,03 \%$ \\
\hline Necessidade & 08 & $13,79 \%$ \\
\hline Total & 58 & $100 \%$ \\
\hline
\end{tabular}

Fonte: Dados da pesquisa.

Em conformidade a Tabela 1, são variados os aspectos e motivações que conduziram as professoras para a carreira docente, ora decorrentes de fatores pessoais, Recebido em: 18/01/2021 
ora por influências oriundas do ambiente no qual se encontravam inseridas. Sendo assim, dentre as categorias emergentes, pontua-se a "Afinidade com a profissão", a qual obteve o maior percentual, sendo este equivalente a 55,17\%, seguida das categorias "Influências" e "Necessidade", com percentual de 31,03\% e 13,79\%, respectivamente. Destaca-se este aspecto em conformidade a Bedin e Del Pino (2018, p. 224), pois a profissão professor, permeada por processos essencialmente culturais e sociais, "apresenta significados e experiências que se inter-relacionam com o contexto em que é exercida e com a formação, considerando a identidade do próprio profissional".

Neste contexto, por meio de tal indagação, buscou-se compreender as memórias e as histórias que conduziram o grupo de professoras a cursar Pedagogia, bem como entender as representações e os sentimentos desta escolha. No concerne desta decisão, em menção a categoria "Afinidade com a profissão", pode se constatar nas narrativas das professoras envolvidas que as motivações para o ingresso na carreira docente estão correlacionadas a valores altruístas e de realização pessoal. Isto é, as colocações docentes estão alicerçadas em características como dom e vocação, alimentadas desde tenra idade, sendo evidenciadas nos excertos: "desde criança sempre quis ser professora" - Fala da professora PC1; "nas brincadeiras de criança, sempre queria ser a professora" - Fala da professora PC2; "desde pequena sempre gostava de ajudar minha irmã nos temas" - Fala da professora PA1.

Além do mais, assim como Dotta (2006, p. 64) reitera que a escolha pela profissão perpassa pelo entusiasmo e pela realização ao ver o estudante se desenvolver e tornar-se "alguém na vida, ser uma pessoa melhor para ele e para a sociedade a sua volta", na entrevista uma parcela do grupo de professoras também aponta o contentamento ao acompanhar este processo. Nesse sentido, quiçá a escolha das professoras seja pela compreensão do profissional da educação como um sujeito que visa contribuir para o bem comum. Sendo assim, conforme Valle (2006, p. 185), o status da profissão professor está "associado à singularidade da função social que deve exercer e a uma certa identidade docente, em que o mito do progresso coletivo confunde-se com o projeto e as ambições individuais".

Já a categoria "Influências" é exercida no seio familiar, por incentivo de amigos próximos, ao decorrer da trajetória escolar, admiração a um professor, ou, ainda, durante o estágio supervisionado no Magistério ou no curso de Pedagogia. Tais 
Edição Especial: I SSAPEC - Simpósio Sul-Americano de Pesquisa em Ensino de Ciências ISSN: 2595- $4520 \quad$ Vol. 4, n. 3. 2021

justificativas vão ao encontro das pesquisas de Gatti e Barreto (2009), visto que as pesquisadoras apontam como argumentos mais comuns a esta escolha a influência familiar ou a de um bom professor. Neste contexto, à caráter de exemplo, elenca-se umas das narrativas que exemplifica as afirmações mencionadas: "minha amiga comentou que iria cursar magistério, e me convidou... me matriculei na escola e acabei gostando" - Fala da professora PA2. Em síntese, destaca-se que o professor constrói a sua identidade docente por meio de referências e de influências de seu contexto sociocultural; logo, perpassam esta escolha "sua história familiar, sua trajetória escolar e acadêmica, sua convivência com o ambiente de trabalho, sua inserção cultural no tempo e no espaço" (CUNHA, 1997, p. 189).

Neste viés, a última categoria inerente a indagação consiste na "Necessidade"; isto porque a escolha de uma dada profissão não remete exclusivamente as características próprias da personalidade do indivíduo, como: disposição, aptidão, interesse e outros, mas depende, também, do contexto em que o mesmo se insere. De acordo com Vale (2006, p. 179), esta escolha está sujeita ao fato do indivíduo "ter nascido num determinado momento histórico e num certo ambiente sociocultural, definido por elementos estruturais bem precisos: de ordem econômica, política e educacional". A autora mencionada ressalva que a escolha pela carreira docente pode ser decorrente da impossibilidade de concretizar outro projeto, como também observado no Quadro 2, quando as professoras PB1 e PB2 ressaltam o interesse em seguir carreiras como: turismo, secretariado executivo e fisioterapia, porém implicações financeiras ao decorrer do processo interferiram na concretização deste sonho, e as direcionaram ao magistério.

Não obstante, com o propósito de aprofundar as reflexões a respeito do questionamento supracitado, na entrevista com o grupo buscou-se também averiguar se as professoras possuíam expectativas diante da possibilidade de exercer outra atividade profissional. Frente a esta interrogação, o grupo de professoras, em sua totalidade, pontuou estar realizado profissionalmente, bem como não possuir interesse e/ou expectativas em seguir outra profissão. No entanto, em suas colocações ao longo da entrevista, emergiram questões como a desvalorização profissional e os desafios presentes no âmbito escolar no que se refere as particularidades do respectivo nível de 
ensino, bem como a abordagem dos conhecimentos específicos e, dentre outras aspectos, o baixo fomento a formação continuada de professores.

Neste viés, com o propósito de analisar a concepção do grupo de professoras em relação ao ensino de Ciências da Natureza no início do processo de escolarização, no que tange a promoção do acesso e a mediação do conhecimento científico, a partir de suas memórias, buscou-se compreender se as professoras colaboradoras da pesquisa enquanto estudantes da Educação Básica gostavam das aulas de Ciências. As respostas obtidas estão representadas no Quadro 3:

Quadro 3 - Respostas das professoras colaboradoras em relação as suas memórias a respeito da área quando alunas na Educação Básica.

\begin{tabular}{|cl|}
\hline Prof. & \multicolumn{1}{c|}{ Colocações extraídas da entrevista } \\
\hline PA1 & $\begin{array}{l}\text { Sim. Por ter contato direto com a natureza, gostava muito de conhecer mais } \\
\text { sobre as plantas, os animais e o funcionamento do corpo humano. }\end{array}$ \\
\hline PA2 & Sim, pois fazíamos várias atividades práticas. \\
\hline PB1 & $\begin{array}{l}\text { Dependia muito como de como eram trabalhadas as aulas de Ciências, das } \\
\text { dinâmicas e práticas (quase sempre ausentes) desenvolvidas pelo professor, } \\
\text { mas gostava sim. }\end{array}$ \\
\hline PB2 & Sim. Porque são aulas mais práticas e que tratam de assuntos do cotidiano. \\
\hline PC1 & $\begin{array}{l}\text { Sim. Era o momento de ter uma aula diferente das demais. Usávamos o } \\
\text { laboratório, fazíamos pesquisa de campo, tabelávamos dados coletados... }\end{array}$ \\
\hline PEC1 & $\begin{array}{l}\text { Sim, gostava e gosto. É um mundo cheio de complexidade e riquíssimo. } \\
\text { aprendizados. }\end{array}$ \\
\hline PC2 & $\begin{array}{l}\text { Sim. Satisfaz, ainda a curiosidade, pois graças a ela, hoje posso ler na tela de } \\
\text { um computador. Atualmente, muitas doenças foram descobertas e controladas } \\
\text { para a nossa qualidade de vida. }\end{array}$ \\
\hline
\end{tabular}

Fonte: Dados da pesquisa.

Considerando as respostas descritas no Quadro 3, observa-se que o grupo de professoras, em sua totalidade, demonstra afinidade com a respectiva área do conhecimento. Neste sentido, com ênfase no posicionamento da professora PA1, pontua-se que o seu interesse em Ciências deriva da proximidade com elementos e fenômenos que permeiam a natureza. Isto é, a mesma possui curiosidade em relação ao estudo sobre as plantas e os animais, assim como o funcionamento do corpo humano. Ademais, com semelhanças a este posicionamento, destaca-se a professora PB2, visto que as suas lembranças remetem a assuntos relativos ao seu cotidiano. Deste modo, supõe-se que a concepção das professoras PA1 e PB2 em relação ao ensino de Ciências Recebido em: 18/01/2021

Aceito em: 24/02/2021 
Edição Especial: I SSAPEC - Simpósio Sul-Americano de Pesquisa em Ensino de Ciências ISSN: 2595- $4520 \quad$ Vol. 4, n. 3. 2021

da Natureza estão correlacionadas a compreensão dos fenômenos presentes no cotidiano, no intuito de agir de forma consciente e responsável com base nos conhecimentos adquiridos ao longo dos processos de ensino e aprendizagem.

Não obstante, frente à contextualização do conhecimento científico, especialmente nos anos iniciais do Ensino Fundamental, Lorenzetti e Delizoicov (2001, p. 6) ressaltam a necessidade de a abordagem pedagógica neste nível de ensino ocorrer mediante a contemplação de elementos e de fenômenos presentes no cotidiano dos estudantes, visto que possibilita aos mesmos "identificar os significados que os conceitos científicos apresentam". No entanto, embora seja um elemento comum nas narrativas das professoras mencionadas, estas possuem implicações distintas no cotidiano escolar. Isto é, por meio da observação do ambiente escolar e da prática pedagógica, pode-se evidenciar que enquanto a professora PA1 buscou promover espaços de discussão e de reflexão a partir de questões que emergem deste contexto, poucos indícios em relação a área de Ciências da Natureza foram observados nas aulas da professora PB2, visto que a mesma pouco propiciou subsídios para a aproximação do "saber científico do cotidiano e da vida do aluno" (PIZARRO; JUNIOR, 2016, p. 209).

Todavia, uma análise detalhada dos excertos do Quadro 3, os quais estão articulados às colocações da professora PB2 na entrevista, evidencia um entendimento no qual o conhecimento científico perpassa questões práticas atreladas ao cotidiano. Porém, a mesma não exemplifica esta questão em seu discurso, aspecto que possibilita acreditar que há falta de clareza ou, ainda, de segurança em relação ao ensino de Ciências da Natureza nos anos iniciais do Ensino Fundamental, diferentemente da professora PA1, uma vez que esta, ainda no questionário, aponta algumas questões de estudo relativas a essa área do saber. Indubitavelmente, esta falta de clareza frente a área e a insegurança por parte da professora PB2 ocasionaram reflexos contundentes no cotidiano escolar, especialmente em relação a área de conhecimento em discussão.

Destarte, ainda em referência ao Quadro 3, pontua-se semelhanças bastante significativas em relação as respostas destacadas pelas professoras PA2, PB1, PB2 e PC1, como, por exemplo, o interesse nesta área em função da realização de atividades práticas. Desta forma, as professoras mencionadas compreendem que a realização de atividades experimentais se configura como uma possibilidade de mobilizar o estudante nos processos de ensino e aprendizagem, e de fomentar a participação ativa ao longo 
deste processo. Assim, salienta-se que a experimentação no ensino de Ciências se constitui como uma possibilidade de transpor a abordagem pautada na memorização e na reprodução de assuntos relacionados a área, bem como mobilizar o estudante ao decorrer do processo de construção do conhecimento, transcendendo a postura passiva ao longo deste.

Considerando as colocações das professoras mencionadas sobre a realização de atividades experimentais, especialmente nesta área, percebe-se que esta encontra-se comumente associada as necessidades cognitivas intrínsecas dos estudantes, as quais, além dos fatores motivadores, estão diretamente vinculadas a realização de atividades em grupo, e, portanto, corroboram com a troca entre pares e configuram-se como uma atividade mediadora das interações sociais (RAMOS; ROSA, 2016). Não obstante, Pozo e Crespo (1998) reiteram que o ensino de Ciências sob o enfoque da experimentação proporciona ao estudante a explicação por meio de modelos e da integração hierárquica dos conhecimentos científicos articulados a vivência dos estudantes. Deste modo, os processos de ensino e aprendizagem dos conhecimentos científicos perpassam a elaboração de modelos, no qual fenômenos da natureza são simulados e postos ao diálogo, no intuito de ressignificar os conhecimentos prévios sobre o mesmo.

Este aspecto também é pontuado por Lorenzetti e Delizoicov (2001), visto que a experimentação no ensino de Ciências tende a atividades potencialmente significativas aos sujeitos na medida em que colaboram para a compreensão, a sistematização e a apropriação do conhecimento científico. Ademais, também é preciso destacar que a realização de atividades experimentais no ensino de Ciências deve ocorrer por meio de objetivos de aprendizagem específicos propostos a cada atividade, de modo que ao se correlacionar a teoria à experimentação se proporcione a estes "vivenciar as etapas do fazer científico" (BERGMANN et al., 2017), uma vez que a experimentação no ensino de ciências potencializa "a busca pelo conhecimento, a ressignificação do saber e o amadurecimento crítico e autônomo dos alunos" (BEDIN, 2019, p. 104).

Destarte, apesar de o grupo de professoras afirmar que compreende a importância da realização de atividades voltadas à experimentação, não se observou esta ação em sua prática docente. Neste contexto, o grupo aponta um conjunto de motivos, como a falta de materiais e espaços específicos para a realização destas atividades, visto que em nenhuma das três escolas envolvidas as professoras dispõem de tais materiais. Deste 
modo, observa-se a imposição de barreiras, que na percepção das professoras, se configura como um obstáculo de difícil superação. Frente a este quesito, na perspectiva de Bachelard (1996), estas barreiras mencionadas se constituem como obstáculos epistemológicos e se tornam intransponíveis; logo, em consonância com o contexto no qual as professoras se inserem, estes tendem a se configurarem como um dos fatores mais decisivos, sendo necessário diferenciá-los e qualificá-los.

Em contrapartida, emerge na resposta da professora PB1 uma das grandes problemáticas da área. Isto porque, tanto a professora PB1 quanto as professoras PC1 e PEC1 salientam que para estimular o interesse e a curiosidade no aluno sobre uma determinada área ou objeto de estudo requer, sobretudo, distintas estratégias e metodologias de ensino, como dinâmicas de grupo e atividades práticas, em sua abordagem. Todavia, estas propostas estão pouco presentes no cotidiano escolar, o que tem contribuído para o desinteresse e a desmotivação dos estudantes no processo de construção do conhecimento científico. Com vistas a este posicionamento, ressalta-se que, embora se compreenda a necessidade da diversificação das estratégias pedagógicas no ensino de Ciências, tal concepção não se reflete no espaço escolar e nas aulas da professora PB1, e o mesmo ocorre com as professoras PA2, PB2 e PC1. Afinal, ao decorrer do período de observação do espaço escolar, evidenciou-se a predominância de abordagens embasadas no livro didático, em impressões e no uso do quadro.

Ao tocante, ressalva-se que a professora PEC1, embora possua dificuldades, possivelmente pelo fato de ainda estar em processo de formação inicial, buscou alternativas para fomentar o interesse e a participação dos estudantes nos processos de ensino e aprendizagem. Desta forma, o estudante, mediante o acesso e a mediação do conhecimento científico, torna-se capaz de refletir sobre a amálgama de saberes, no sentido de realizar uma leitura e um interpretação do seu entorno social, bem como do processo de agir de forma consciente e responsável sob ele (OVIGLI; BERTUCCI, 2009). Ao encontro desta discussão, apresenta-se outro excerto do diário de bordo: domésticos, a professora PEC1 disponibiliza aos estudantes jogos, atividades lúdicas, cantigas e materiais impressos em referência a temática mencionada. Todavia, a mesma ao decorrer da explicação do objeto de conhecimento, apesar da iniciativa pouco contou com o envolvimento e a participação dos estudantes neste processo, visto que apenas fazia a leitura deste material (Excerto do diário de bordo da pesquisadora, 2019). 
Ademais, ainda frente a esta questão, também se observou na prática docente uma predominância de ações voltadas ao desenvolvimento de competências e de habilidades relativas as áreas de Linguagens e Matemática, enquanto que assuntos voltados a área de Ciências foram poucos explorados. Portanto, mesmo que de modo implícito, pode-se ilustrar que, embora as professoras compreendam a importância do ensino de Ciências para a formação do sujeito, pouco têm contribuído para a aproximação gradativa ao mesmo, evidenciando uma contradição no espaço escolar (VIECHENESKI; CARLETTO, 2011). Nesse sentido, destaca-se que indubitavelmente estas são questões importantes, uma vez que a Base Nacional Comum Curricular (BNCC) assevera que:

É necessário destacar que, em especial nos dois primeiros anos da escolaridade básica, em que se investe prioritariamente no processo de alfabetização das crianças, as habilidades de Ciências buscam propiciar um contexto adequado para a ampliação dos contextos de letramento (BRASIL, 2017, p. 331).

Apesar de considerar uma abordagem intradisciplinar mais profícua no sentido de contemplar diferentes áreas de conhecimento no estudo de um respectivo objeto, pontua-se que a BNCC preconiza o processo de alfabetização das crianças, especialmente nos dois primeiros anos escolar. Em contraposição, pontua-se que priorizar uma dada área não consiste em desdenhar os saberes relativos das demais, pois todos os conhecimentos são importantes para a formação integral do estudante. Nesse contexto, os pesquisadores Nigro e Azevedo (2011, p. 705) ressaltam que os professores possuem dificuldades em gestar o "alto peso que é dado ao ensino de Língua Portuguesa", ocasionando em "muito esforço despendido para o ensino de leituraescrita", desmerecendo os demais saberes, tão importantes quanto para a formação do indivíduo.

Em relação a posicionamento da professora PC2, destaca-se que a mesma evidencia as contribuições da Ciência para a sociedade. Igualmente, Viecheneski e Carletto (2013) salientam que esta área de conhecimento é de suma importância no sentido de fomentar o interesse dos estudantes pelas carreiras científicas, e, deste modo, formar sujeitos capazes de produzir conhecimentos, tanto científicos quanto tecnológicos, corroborando ao desenvolvimento econômico e social do país. No entanto, 
Edição Especial: I SSAPEC - Simpósio Sul-Americano de Pesquisa em Ensino de Ciências ISSN: 2595- $4520 \quad$ Vol. 4, n. 3. 2021

embora se compreenda a importância desta área para a formação do sujeito, no sentido de contribuir para o avanço científico e tecnológico, acredita-se à luz da observação que esta professora pouco propiciou a mediação do conhecimento científico na turma em que é responsável.

Diante de tais apontamentos, salienta-se que o grupo composto por 7 professoras possui, de certo modo, tanto memórias quanto lembranças bastante significativas em relação ao ensino de Ciências da Natureza, quando estudantes da Educação Básica. Todavia, os achados da pesquisa, tanto das observações e descrições no diário de bordo em relação ao cotidiano escolar quanto aos materiais de um grupo de estudantes das respectivas turmas envolvidas, possibilitam o entendimento de que as docentes colaboram com poucas ações significativas para a promoção e a discussão de saberes relacionados a esta área do conhecimento.

\section{CONCLUSÃO}

Ao término, destaca-se que apesar de o grupo possuir memórias e lembranças positivas em relação ao ensino de Ciências quando estudantes da Educação Básica, estas pouco refletem na prática pedagógica no cotidiano escolar, já que se observou poucos indícios da sua promoção nos níveis de ensino supracitados. No que tange os indicativos que direcionaram o grupo à escolha da profissão, destaca-se quesitos como: afinidade com a profissão, influências e necessidade, visto que se salienta que estes são, ora decorrentes de fatores pessoais, ora por influências oriundas do ambiente em que se encontravam inseridas. Ademais, o grupo em sua totalidade demonstra estar profissionalmente contentes com a profissão, embora reiteram sobre uma série de desafios que perpassam pelo ambiente escolar.

Diante de tais considerações, evidencia-se a necessidade de ações voltadas à formação continuada de professores, no intuito de dialogar em relação à importância desta temática para a formação do sujeito, bem como orientar a ação docente em relação ao processo de mediação do conhecimento científico com vistas a formação de um indivíduo cientificamente alfabetizado. Afinal, mediante a promoção de espaços para a reflexão, os quais contemplam as narrativas e as posturas dos professores, bem como as de suas memórias no decorrer deste processo, propõe-se momentos para que os mesmos se reconheçam e se autoavaliem como profissionais da educação, no que tange as suas Recebido em: 18/01/2021 
Edição Especial: I SSAPEC - Simpósio Sul-Americano de Pesquisa em Ensino de Ciências

ISSN: 2595- $4520 \quad$ Vol. 4, n. 3. 2021

motivações e as suas ações em prol da formação do sujeito, de modo a contribuir para uma mudança epistemológica da profissão professor.

\section{REFERÊNCIAS}

BEDIN, Everton. Filme, Experiência e Tecnologia no Ensino de Ciências Química: uma sequência didática. Revista de Educação, Ciências e Matemática, v. 9, n. 1, 2019.

Disponível em:

http://publicacoes.unigranrio.edu.br/index.php/recm/article/view/4280/2882. Acessado em: 22 dez. 2020.

BEDIN, Everton; DEL PINO, José Claudio. Interações e intercessões em rodas de conversa: espaços de formação inicial docente. Revista Brasileira de Estudos Pedagógicos, v. 99, n. 251, p. 222-238, 2018. Disponível em:

https://doi.org/10.24109/2176-6681.rbep.99i251.3383. Acessado em: 22 dez. 2020.

BERGMANN, Adriana Belmonte et al. Atividades experimentais no ensino de ciências nos anos iniciais do ensino fundamental: percepção de um grupo de professores.

Enseñanza de las ciencias: revista de investigación y experiencias didácticas, $n$.

Extra, p. 2065-2070, 2017. Disponível em:

https://www.raco.cat/index.php/Ensenanza/article/view/337505. Acesso em: $19 \mathrm{dez}$. 2020.

BRASIL. Base Nacional Comum Curricular. Educação é a Base. Brasília, MEC/CONSED/UNDIME, 2017. Disponível em:

http://basenacionalcomum.mec.gov.br/wp-content/uploads/2018/02/bncc-20dezsite.pdf. Acesso em: 19 dez. 2020.

CACHAPUZ, António et al. A necessária Renovação do Ensino das Ciências. 3 ed. São Paulo: Cortez, 2005.

CUNHA, Maria Isabel. O bom professor e sua prática. $5^{\text {a }}$ ed. Campinas: Papirus, 1997. 
FUMAGALLI, Laura. O ensino de ciências naturais no nível fundamental de educação formal: argumentos a seu favor. Didática das ciências naturais: contribuições e reflexões. Porto Alegre: ArtMed, p. 13-29, 1998.

GATTI, Bernadete Angelina; BARRETO, Elba Siqueira de Sá. Professores: aspectos de sua profissionalização, formação e valorização social. Brasília, DF: Unesco, 2009.

GOLDSCHMIDT, Andrea Inês; JÚNIOR, José Luiz Goldschmidt; LORETO, Élgion Lúcio. Concepções referentes à ciência e aos cientistas entre alunos de anos iniciais e alunos em formação docente. Revista Contexto \& Educação, v. 29, n. 92, p. 132-164, 2014. Disponível em: https://doi.org/10.21527/2179-1309.2014.92.132-164. Acessado em: 15 nov. 2020.

KRASILCHIK, Myriam; MARANDINO, Martha. Ensino de ciências e cidadania. Moderna, 2007.

KURZ, Débora L.; BEDIN, Everton. As potencialidades das tecnologias de informação e comunicação para a área das ciências da natureza: uma investigação em periódicos da área: Interfaces da Educação, v. 10, n. 30, p. 246-267, 2019b. Disponível em: https://doi.org/10.26514/inter.v10i30.3932. Acesso em: 12 ago. 2020.

LORENZETTI, Leonir; DELIZOICOV, Demétrio. Alfabetização científica no contexto das séries iniciais. Ensaio Pesquisa em Educação em Ciências (Belo Horizonte), v. 3, n. 1, p. 45-61, 2001. Disponível em: http://dx.doi.org/10.1590/1983-21172001030104. Acesso em 19 dez. 2020.

MARANDINO, Martha; KRASILCHIK, Myriam. Ensino de ciências e cidadania. São Paulo: Moderna, 2004, 87 p.

MINAYO, Maria Cecília de Souza; GUERRIERO, Iara Coelho Zito. Reflexividade como éthos da pesquisa qualitativa. Ciência \& Saúde Coletiva, v. 19, p. 1103-1112, 
Edição Especial: I SSAPEC - Simpósio Sul-Americano de Pesquisa em Ensino de Ciências

ISSN: 2595- $4520 \quad$ Vol. 4, n. 3. 2021

2014. Disponível em: https://www.scielosp.org/pdf/csc/2014.v19n4/1103-1112/pt.

Acesso em: 17 nov. 2020.

NIGRO, Rogério Gonçalves; AZEVEDO, Maria Nizete. Elementary science education: profile of a group of teachers experiencing continuous formation in a scientific literacy context. Revista Ciência e Educação, v. 17, n. 3, p. 705 - 720, 2011. Disponível em: http://www.scielo.br/pdf/ciedu/v17n3/a12v17n3.pdf. Acesso em: 19 dez. 2020.

OVIGLI, Daniel Fernando Bovolenta; BERTUCCI, Monike Cristina Silva. O ensino de Ciências nas séries iniciais e a formação do professor nas instituições públicas paulistas. Simpósio Nacional de Ensino de Ciências e Tecnologia. Anais. Ponta Grossa: UTFPR, p. 1595-1612, 2009.

PIZARRO, Mariana Vaitiekunas; JUNIOR, Jair Lopes. Indicadores de alfabetização científica: uma revisão bibliográfica sobre as diferentes habilidades que podem ser promovidas no ensino de ciências nos anos iniciais. Investigações em Ensino de Ciências, v. 20, n. 1, p. 208-238, 2016. Disponível em:

https://www.if.ufrgs.br/cref/ojs/index.php/ienci/article/view/66/42. Acesso em: 19 dez. 2020.

SARMENTO, Manuel Jacinto. O estudo de caso etnográfico em educação. 2011.

VALLE, Ione. Carreira do magistério: uma escolha profissional deliberada? Revista Brasileira de Estudos Pedagógicos, v.87, n. 216, p. 178-187, 2006. Disponível em: http://rbep.inep.gov.br/index.php/rbep/article/view/792/767. Acesso em: 30 out. 2020.

VIECHENESKI, Juliana Pinto; CARLETTO, Marcia. Por que e para quê ensinar ciências para crianças. Revista Brasileira de Ensino de Ciência e Tecnologia, v. 6, n. 2, 2013. Disponível em:

https://pdfs.semanticscholar.org/07a4/f43ce689b9612266a37868bec725c5a1adb4.pdf. Acesso em: 19 dez. 2020. 